\title{
COMO SE COMPORTAR EM UMA ENTREVISTA DE EMPREGO
}

\section{ARTIGO ORIGINAL}

MOREIRA, Andreia Aparecida Silva ${ }^{1}$

MOREIRA, Andreia Aparecida Silva. Como se comportar em uma entrevista de emprego. Revista Científica Multidisciplinar Núcleo do Conhecimento. Ano 05, Ed. 01, Vol. 09, pp. 16-34. Janeiro de 2020. ISSN: 2448-0959, Link de acesso: https://www.nucleodoconhecimento.com.br/administracao/entrevista-deemprego

\section{RESUMO}

O presente trabalho tem o objetivo de descrever quais são os passos para fazer uma boa entrevista de emprego gerando confiança e tranquilidade em relação ao processo seletivo. Além de entender como elaborar um currículo chamativo e conhecer as técnicas da entrevista comportamental por competência. O problema de pesquisa busca solucionar a seguinte questão: como se comportar em uma entrevista de emprego? Para isso foi feito uma entrevista com um HeadHunter e uma revisão bibliográfica em livros, teses, dissertações e artigos disponíveis na internet. Os resultados mostram que se o candidato se preparar antes de ir para o processo seletivo, entendendo os passos, o comportamento e como reagir diante dos mesmos, terá sucesso e poderá ser aprovado ou estar em posição de destaque. Concluiu-se também que o currículo é o primeiro passo para chamar a atenção do recrutador, por isso foi descrito com detalhes como deve ser elaborado, pois o mesmo é o cartão de visita do candidato. Por fim são muitas as dúvidas quando se fala em comportamento em entrevista, mas o importante é ser verdadeiro e estar bem preparado.

1 Mestre em Administração pela FEAD de Belo Horizonte, Pós-Graduada em Controladoria e Finanças Empresariais pela UFLA e Graduada em Administração pela UEMG de Cláudio. 
Palavras Chave: Processo seletivo, técnicas para entrevista, comportamento, competência, currículo.

\section{INTRODUÇÃO}

O processo de agregar pessoas (recrutamento e seleção) é o primeiro passo para inserir as pessoas dentro de uma organização. É através do recrutamento que são lançadas as vagas no mercado, recebendo os currículos para que seja feita a seleção que por sua vez escolherá o candidato que tem o perfil ideal para a vaga, ou seja, recrutamento é a divulgação da vaga no mercado de trabalho e seleção é a preferência pelo candidato por meio de técnicas e testes comportamentais.

Existe o recrutamento externo que significa procurar no mercado de recursos humanos $(\mathrm{RH})$ o profissional desejado, quando na estrutura interna não há candidatos para promover. E o recrutamento interno que é aquele onde os funcionários que já trabalham na empresa são escolhidos para participar do processo seletivo para preenchimento das vagas existentes. Abordaremos aqui o recrutamento externo, pois buscamos estudar como se comportar em uma entrevista de emprego. No recrutamento interno já se conhece o comportamento do candidato pelo fato do mesmo já ter sido entrevistado para outro cargo.

Os recrutadores estão cada vez mais exigentes fazendo uso de vários métodos e técnicas para escolha do candidato ideal. Por isso as pessoas devem estar bem informadas de como se comportar em uma entrevista de emprego. Começando pela imagem, postura, gestos corporais, as respostas que vão dar as perguntas e também entender sobre a entrevista comportamental por competência.

A empresa em estudo é o Instituto Brasileiro de Recolocação AÇÃOHUNTER constituída em 15/12/1999, na cidade de Belo Horizonte Minas Gerais. É uma empresa para quem procura se recolocar no mercado de trabalho. Possui 5 funcionários mais o proprietário. O principal objetivo é assessorar os profissionais em seus planejamentos de carreira, preparando-os para prospectar as oportunidades no mercado de trabalho. Fornecer metodologias para obter sucesso em uma entrevista e 
elaboração de currículo. Os profissionais que estão procurando recolocação fazem um contrato com a AÇÃOHUNTER com duração de um ano e o Instituto irá encaminhar o currículo para as vagas disponíveis no mercado.

O nome dado ao profissional que atua neste ramo de atividade é HeadHunter "caçador de talentos", ou seja, eles treinam e procuram os melhores talentos no mercado de trabalho e os recoloca nas empresas.

Diante do exposto acima tem o seguinte problema: como se comportar em uma entrevista de emprego?

Para responder o questionamento levantado tem-se a seguinte hipótese:

1. Se preparar para uma entrevista e entender as técnicas, estudar sobre a entrevista comportamental por competência, se preocupar com a imagem, postura e comportamento garantem destaque no processo seletivo, podendo $o$ candidato ter mais chance de ser aprovado.

O objetivo geral consiste em saber quais são os passos para fazer uma boa entrevista de emprego gerando confiança e tranquilidade em relação ao processo seletivo. E os objetivos específicos consistem em: estudar os fundamentos teóricos sobre técnicas de entrevista, conceituar e entender a entrevista por competência, saber como construir um currículo chamativo.

O estudo é de extrema importância, pois a entrevista é um grande passo para a aprovação no processo seletivo e quando conhecemos formas de nos comportar e técnicas para aplicar, passamos a ter uma visão diferente e até conseguir o tão sonhado emprego. O presente trabalho pode servir de fonte de dados e pesquisa para as pessoas interessadas em aprimorar os conhecimentos na área de recrutamento e seleção e as que desejam melhorar seu comportamento nas entrevistas.

A metodologia consiste em levantamento de dados através de entrevista com um HeadHunter além de uma revisão de literatura com pesquisas em livros, dissertações, artigos e monografias sobre o tema em estudo. Caracteriza-se também como uma 
pesquisa descritiva, pois busca descrever como se comportar em uma entrevista de emprego e quais as técnicas a serem utilizadas pelo candidato.

O artigo está estruturado da seguinte forma: introdução contendo o problema de pesquisa, o objetivo geral e específicos, a hipótese e a justificativa. O referencial teórico abordando o tema em estudo baseando-se em autores tais como: Rabaglio (2004), Araújo (2012) e Chiavenato (2014), dentre outros. Em seguida a metodologia baseada em levantamento de dados. Análise e tabulação dos dados com aplicação de entrevista e finalizando a conclusão e as referências que serviram de suporte para o desenvolvimento deste artigo.

\section{REFERENCIAL TEÓRICO}

Na presente parte será explanado conceitos de recrutamento e seleção, definição de entrevista por competência, como se comportar em uma entrevista de emprego e relatos de como elaborar um currículo atrativo.

\section{RECRUTAMENTO E SELEÇÃO}

Os conceitos de recrutamento e seleção são diferentes entre si apesar dos dois termos virem sempre juntos. Chiavenato (2004) diz que recrutamento são os meios utilizados para o lançamento das vagas no mercado de trabalho, dentre estes podemos citar: anúncios em jornais, revistas, televisão, rádio, cartazes, HeadHumter, sites de emprego como CATHO, Empregos.com, vagas.com, opções no site da empresa para cadastrar o currículo no trabalhe conosco, entre outros.

Para Limongi-França e Arellano (2002) recrutamento pode ser entendido como a procura de candidatos e incentivo aos mesmos a se candidatar para as vagas existentes em uma empresa. É o primeiro passo para preencher uma vaga.

De acordo com Caxito (2008), a seleção faz a escolha do candidato que possui o perfil ideal para a vaga existente em uma organização. É através das técnicas de seleção que se identifica os candidatos que estão de acordo com o perfil procurado. 
São quatro os estágios do processo de seleção: atração: estágio de atrair candidatos, responsabilidade dos profissionais de recrutamento. Triagem: escolha dos candidatos que possuem o perfil da vaga e desclassificação dos que não são qualificados. Avaliação: analise dos candidatos que foram triados, essa análise inclui perfil, qualificações, experiências, dentre outros aspectos. Decisão: ações desenvolvidas para a escolha do candidato ideal para a vaga disponível. (CAXITO, 2008).

De acordo com Chiavenato (2014) podemos fazer o recrutamento e seleção de duas formas, dando oportunidade para os colaboradores que já atuam na organização este é denominado recrutamento interno que por sua vez possui as seguintes vantagens: custo mais baixo, compreensão das habilidades do candidato, moral elevada, motivação, oportunidade de crescimento, reconhecimento, dentre outros. E temos também o recrutamento externo que é aquele onde busca-se profissionais no mercado de trabalho, ele tem como vantagens: aumento do capital intelectual com a contratação de novos talentos, gera oportunidade a pessoas vindas de outras empresas com diferentes pensamentos, habilidades e expectativas, enriquece a cultura da empresa e introduz sangue novo na organização.

Existem algumas técnicas para a escolha do melhor candidato para a vaga tais como entrevistas, provas de conhecimento e técnicas vivencias. Cada uma delas tem como finalidade analisar aspectos específicos da personalidade dos candidatos as vagas disponíveis. (CHIAVENATO, 2014).

Chiavenato (2004) aponta algumas vantagens da entrevista, tais como proximidade do entrevistador com o candidato, permitindo extrair informações mais precisas e claras. Fazendo uma análise total e avaliação das reações do candidato a determinados aspectos como medo, expressão corporal e verbal, imagem, postura entre outros.

De acordo com Limongi-França e Arellano (2002) a entrevista de seleção deve ser bem estruturada e seguir alguns passos indicados fará com que a mesma seja mais bem sucedida, os passos são: fazer um quebra-gelo, perguntar dados familiares, 
sociais, escolaridade, experiência profissional, pontos de melhoria e pontos fortes do candidato, análise de interesse pelo cargo, encerramento e avaliação da entrevista.

Porém quando si fala em seleção hoje muitas empresas estão optando pela seleção por competência, mesmo que a organização não tenha implantado a gestão por competência ela pode utilizar este tipo de técnica. Muitas empresas buscam experiências em seus candidatos, pois acredita que os mesmos darão um retorno mais rápido ao que a organização necessita. Mas em um ambiente empresarial com continuas transformações em que a vantagem competitiva está na atuação do colaborador alguma competência tem sido fundamental para a escolha do candidato, tais competências podem ser: visão sistêmica e empreendedora, capacidade de resolução de problemas bem como conflitos, saber lidar com as mudanças, relacionamento interpessoal e comunicação. (ARAUJO, 2012).

Ainda de acordo com Araújo (2012 p. 29):

"A empresa que adotou a seleção por competência, naturalmente vai adaptar esta metodologia ao modelo de gestão que implementou. Pode ser usada também para qualquer cargo, do operacional ao executivo, com decisões e planos estratégicos para cada cargo. A competência comunicação interpessoal, por exemplo, está sendo investigada através da entrevista comportamental. Então faremos perguntas abertas específicas com foco nesta competência, para observar sua presença ou ausência no repertorio comportamental do candidato. "Conte-me sobre uma situação onde você teve um problema de relacionamento com sua equipe de trabalho ou com um cliente interno e o que você fez? ". "Relate uma situação onde você teve que administrar uma incompatibilidade muito seria com sua liderança, como foi? ". "Fale-me de situações onde você foi muito elogiado pela sua espontaneidade e facilidade de comunicação"? Ou ainda "Conte a maior dificuldade que já administrou na comunicação com um cliente difícil". O que há de comum em todas estas perguntas é que são perguntas abertas específicas com verbos de ação no passado, são perguntas situacionais que investigam 
uma competência específica na experiência passada do candidato". (ARAÚJJ, 2012, p. 29).

Independentemente do tipo de entrevista que você optar para sua empresa ou da técnica a ser utilizada o importante é que você escolha o candidato ideal para a vaga disponível e que este candidato consiga gerar o desempenho que a organização necessita, seja de habilidades, comportamentos e inovação.

\section{COMO SE COMPORTAR EM UMA ENTREVISTA DE EMPREGO}

Um processo seletivo busca colocar a pessoa certa no lugar certo, e na maioria das vezes um perfil comportamental pesa mais do que as competências técnicas ou capacidade intelectual do indivíduo. O primeiro passo na busca de uma oportunidade é estar com seu currículo atualizado, depois buscar por uma vaga que seja adequada a seu perfil. (KENNEDY, 1999).

Segundo Rabaglio (2004) o currículo é uma das ferramentas que serve de guia para o entrevistador, por isso elaborar um bom currículo também é um diferencial do candidato, além de ser o primeiro requisito que vai atrair o recrutador para o seu perfil. Nunca coloque coisas no seu currículo que não sejam verdadeiras. Um currículo deve conter esta ordem: cabeçalho contendo nome, endereço, telefone, e-mail, idade. Área de interesse descreva- a de forma direta e clara para que o mercado saiba o que você está buscando. Síntese profissional: faça uma síntese geral do seu currículo, colocando formação, experiências e principais características. Formação: escreva a formação da mais atual para a amis antiga. Idioma: coloque os idiomas que você está cursando e o nível em que está (básico, intermediário, avançado). Experiência profissional: as experiências profissionais devem ser descritas da mais recente para a mais antiga. Se as mesmas forem muitos extensas coloque somente as que estão de acordo com seu objetivo profissional. Ao descrever suas atividades ou experiências seja sucinto, porém completo. É importante lembrar que o currículo pode ter uma ou mais páginas, porém aprenda a ser objetivo, diga o suficiente. Faça uma síntese das principais realizações colocando os resultados e destaque os principais projetos. Cursos Extra Curriculares: descreva seus cursos extracurriculares do mais recente 
para o mais antigo. (Coloque todos os cursos que você fez desde os profissionalizantes até os de curta duração). Certificações: descreva suas certificações da mais recente para a mais antiga. Relate suas premiações, carteira de habilitação, disponibilidade para viagens e mudança de cidade. Formatação: Arial ou Times New Roman 12. Cuidado com erros de português. Foto: Colocar 3x4, mas com terninhos pretos com blusa branca por baixo ou camisa social branca. Mas a foto não é obrigatória. Vide modelo de currículo em anexo.

Antes de uma entrevista busque informações sobre o perfil da empresa a qual você deseja fazer parte. Conhecer a história e sua fundação, missão, visão, seu ramo de atuação se nacional ou não. (Kennedy, 1999).

Primeiro identifique qual o tipo de empresa a qual você busca uma oportunidade, para identificar qual imagem vai transmitir, o ideal seria usar uma roupa mais formal sem chamar muita atenção. Para cargos executivos recomenda-se para mulheres ternos pretos com blusa branca por baixo, sem decotes e scarpin preto. Para cargos normais camisete branca com calça social preta e scarpin preto. Maquiagem leve, unha com esmaltes claros e sem bijuterias. Cabelos limpos e penteados. Para homens em cargos executivos terno preto com camisa branca por baixo, demais cargos camisa social branca e calça social preta. Barba feita e cabelos bem cortados. (LAWSON, 2011).

Ou de acordo com Kennedy (1999) o candidato poderá pesquisar qual o estilo de roupa da empresa e ir para a entrevista de acordo com o mesmo. Ou você pode conjugar a roupa com a cor da logomarca se esta for discreta.

O primeiro passo da entrevista é o quebra gelo, nesta parte o entrevistador pode oferecer uma água, um café, ou comentar algo informal com o candidato sobre acontecimentos importantes para gerar uma sinergia entre os dois, pois muitas vezes os candidatos chegam nervosos, tímidos e com receio, fazendo com que não mostre seu total potencial referido no currículo, o quebra gelo pode ajudar nesta situação. (LAWSON, 2011). 
Feito o quebra gelo será iniciada a entrevista, desta forma o candidato deve se preocupar não só com o que vai dizer, mas principalmente como vai dizer, o ideal é falar o necessário, apenas o que for perguntado e não utilizar gírias. Manter a calma e ser sincero em suas respostas é fundamental. Aponte o que você tem de melhor e quais os pontos você ainda precisa melhorar. (Kennedy, 1999).

Geralmente segundo Rabaglio (2004) a entrevista é dividida em três partes. A primeira é sobre o interesse do candidato na empresa e na vaga, a estrutura familiar e os objetivos sejam eles hobby, pontos fortes, pontos a desenvolver e formação acadêmica. A segunda parte diz respeito as experiências profissionais sendo abordado crescimento organizacional, estabilidade profissional e atividades realizadas na empresa. E a terceira e última etapa diz respeito a entrevista comportamental contendo perguntas abertas que observarão comportamentos passados alinhados ao perfil da vaga futura, ou seja, o entrevistador fará perguntas abertas para que o candidato diga qual foi a situação, como ele reagiu e quais foram os resultados.

No geral em processos de seleção o que mais "pesa" são os resultados que o candidato obteve com experiências anteriores, mas claro, se for o primeiro emprego o recrutador saberá que o candidato não tem experiência e isso não será motivo para ficar em silêncio, o mesmo poderá citar suas experiências no campo acadêmico durante o período de seus estudos. (LAWSON, 2011).

Por sua vez segundo Araújo (2012), com a gestão por competência as empresas ao entrevistarem um candidato observarão seus conhecimentos, habilidades e atitudes, pois o diferencial está na sua atuação profissional e os resultados que o colaborador irá proporcionar à organização, por isso o candidato a uma entrevista deve estudar sobre a entrevista comportamental por competência, nela utiliza-se perguntas abertas sobre habilidades e vivencias do candidato nas empresas onde já trabalhou. Muitas pessoas já vão com respostas prontas para os processos seletivos obedecendo os modelos tradicionais, mas são surpreendidos com outro tipo de técnica (entrevista comportamental por competência) e o foco muda completamente. Onde o candidato deverá relatar conhecimentos, habilidades e atitudes para resolução de problemas 
dentro da empresa. Portanto ao ser convidado para um processo seletivo prepare e entenda suas competências para se sair bem.

O encerramento da entrevista será composto pelo agradecimento e aconselha-se reafirmar o interesse na vaga. No caso de não ser o candidato escolhido não significa que você não tem competência, mas sim, que havia alguém mais adequado naquele momento ao perfil que foi solicitado. (LAWSON, 2011).

\section{METODOLOGIA}

Para responder o problema e atingir os objetivos deste estudo foi realizada uma entrevista com o HeadHunter da empresa AÇÃOHUMTER. De acordo com Gil (1999), página 45 a entrevista constitui-se de:

"Um procedimento racional e sistemático que tem como objetivo proporcionar respostas aos problemas que são propostos. (...) A pesquisa é desenvolvida mediante o concurso dos conhecimentos disponíveis e a utilização cuidadosa de métodos, técnicas e outros procedimento científicos (...) ao longo de um processo que envolve inúmeras fases, desde a adequada formulação do problema até a satisfatória apresentação dos resultados". (GIL, 1999, p. 45).

Realizou-se também uma pesquisa bibliográfica em artigos, monografias, teses disponíveis na internet além de livros sobre a temática pesquisada. Foi realizada também consultas em sites de empregos. Gil (2008 p. 29) diz que "a pesquisa bibliográfica é elaborada com base em material já publicado. Tradicionalmente, esta modalidade de pesquisa inclui material impresso, como livros, revistas, jornais, teses, dissertações e anais de eventos científicos. "

A pesquisa caracterizou-se como descritiva, pois possibilitou descrever como se comportar e quais são os passos para fazer uma boa entrevista de emprego gerando confiança e tranquilidade em relação ao processo seletivo. 
"A pesquisa descritiva expõe características de determinada população ou de determinado fenômeno. Pode também estabelecer correlações entre variáveis e definir sua natureza. Não tem compromisso de explicar os fenômenos que descreve, embora sirva de base para tal explicação". (VERGARA, 2000, p. 47).

A pesquisa foi também qualitativa pois segundo Marconi e Lakatos (2011, p. 269) "a metodologia qualitativa preocupa-se em analisar e interpretar aspectos mais profundos, descrevendo a complexidade do comportamento humano. Fornece análise mais detalhada sobre as investigações, hábitos, atitudes, tendências de comportamento etc.".

Quanto aos fins a pesquisa foi exploratória, pois foi realizada na empresa AÇÃOHUNTER, possibilitando detectar o problema e entendimento do tema em estudo de forma clara e simplificada. De acordo com Vergara (1998, p. 45) "é realizada em área na qual há pouco conhecimento acumulado e sistematizado por sua natureza de sondagem".

O universo da pesquisa foi uma empresa de Recolocação localizada em Belo Horizonte, sendo a amostra representada pelo HeadHunter diretor e proprietário da AÇÃOHUNTER.

Oliveira (2001) apud Boghossian (2012) conceitua headhunter como:

"Um profissional focado em encontrar a pessoa certa para um determinado cargo na empresa. A profissão surgiu nos Estados Unidos após a Segunda Guerra Mundial e lentamente foi se instalando no Brasil a partir da década de 60 , onde só começou a ganhar um mercado expressivo nos anos 90 . Segundo o autor, esse tipo de serviço já faz parte de centenas de empresas de médio e grande porte, atualmente". (OLIVEIRA 2001 apud BOGHOSSIAN 2012, p. 13-14).

Coletados os dados realizou-se a análise e tabulação de forma a atender os objetivos deste trabalho. 


\section{RESULTADOS E DISCUSSÕES}

Várias questões sobre comportamento foram discutidas em uma entrevista com o HeadHunter proprietário da empresa AÇÃOHUNTER: Antônio Carlos Batista, 45 anos, formado em Administração e pós-graduado em Gestão Estratégica de Pessoas, fundador da empresa onde atua a 20 anos.

Quando foi perguntado sobre como deve ser a fase de preparação para o processo seletivo, o HeadHunter disse que é fundamental buscarmos informações sobre a empresa a qual fomos convidados.

Entrevista presencial é um grande passo para aprovação. Devemos, portanto, trata-la como única, ou seja, dedique-se para cada entrevista presencial que for participar. Lembre-se na atualidade, estamos também sujeitos a entrevistas via Skype, telefone e WhatsApp. São fazes que podem eliminar e em algumas vezes triar candidatos. É importante manter-se alinhado ao processo e sempre se atentar para as dicas do entrevistador. Seguir os passos que indicamos deverá trazer maior confiança e tranquilidade em relação ao processo.

- Dica 1: procure no Google, ou qualquer buscador online de sua preferência, informações como história da empresa, ramo de atividade, locais de atuação, nome do diretor geral, nome do diretor de $\mathrm{RH}$, cultura da empresa. Pesquise também sobre quem será seu possível gestor ou superior direto. Lembre-se que o $\mathrm{RH}$ seleciona o profissional que possui perfil parecido ao gestor. Então, ter informações sobre esse profissional e se conectar a ele durante a entrevista serão diferenciais durante o processo.

- Dica 2: procure em suas redes sociais possíveis amigos que trabalhem na empresa. Se encontrar, entre em contato com ele e pergunte sobre a mesma. Pergunte também se existe a possibilidade de indicá-lo para o setor de recursos humanos.

- Dica 3: identidade corporativa - cor e forma de vestir. Cor: entenda qual a cor do logotipo da empresa. Alinhe-se com a cor do logotipo. Tenha cuidado para não vestir a cor do concorrente para o processo seletivo ou caso a logomarca 
tenha cor viva/forte, pois nem sempre a recrutadora entenderá como conexão com a empresa. Se não tiver a cor da empresa, utilize as cores cinza, preto ou branco que são padrão em processos seletivos e não causam prejuízo. Forma de vestir: para entender sobre qual a forma de vestir da empresa que você irá participar do processo seletivo, ligue para a mesma e comente com a recepcionista que você terá uma apresentação, processo ou reunião no dia seguinte e gostaria de saber como as pessoas (do seu nível hierárquico) se vestem. Pesquise também através das ferramentas: Google (Uniforme \#EMPRESA), LinkedIN (Funcionários da Empresa) e Site.

E ainda fez a seguinte observação: para homens, indicamos que participe dos processos seletivos sem nenhuma barba. Salvo exceções em que o profissional identifique que a identidade corporativa da empresa permita isso. Para mulheres indicamos que não utilize esmaltes muito chamativos e roupa muito decotada. Maquiagem leve. Lembre-se que esse é seu primeiro contato com a empresa e conectar-se com a cultura interna é fundamental.

Ao ser interrogado sobre qual o primeiro passo ao iniciar a entrevista ele fez um relato muito importante dizendo que o mundo está repleto de notícias ruins ou desagradáveis. Portanto, indicamos que ao abrir a entrevista, inicie com um verdadeiro sorriso. Lembre-se que grande parte dos processos seletivos são decididos através da empatia entre 0 entrevistador e o candidato. Atitudes comportamentais e valores pessoais conectados com a empresa são tão valorizados quanto à habilidade técnica. De acordo com Rabaglio (2004) durante a entrevista, após responder uma pergunta do entrevistador, não fique pensando se deveria ou não ter respondido dessa ou daquela forma. Lembre-se que uma resposta não será responsável pelo sucesso ou fracasso, então o mais importante é focar e prestar atenção na próxima pergunta do entrevistador.

Sobre os cuidados que devemos tomar na antessala do processo seletivo Carlos aconselhou: tenha muita calma e atenção nas antessalas de processos seletivos. Evite conversar sobre a empresa com os outros candidatos. Alguns recrutadores colocam "espiões" nessa fase do processo para entender o que os candidatos 
realmente pensam sobre a vaga e a organização. Seja objetivo e sempre fale bem da empresa e do processo. Evite conflitos e posições extremadas. É fundamental lembrar que desde a portaria, o candidato está sendo avaliado. Trate todos com cordialidade e respeito, essa atitude será decisiva em uma aprovação.

Interrogado sobre como se comportar durante a entrevista o HeadHunter disse que normalmente ela será dividida em três etapas: 1- IFO (Interesse na empresa Estrutura Familiar - Objetivos) 2- Experiência Profissional 3- Entrevista Comportamental. (Dados obtidos durante entrevista).

\section{IFO - INTERESSE NA EMPRESA, ESTRUTURA FAMILIAR E OBJETIVOS}

I (Interesse) - Interesse no processo seletivo é um dos principais fatores de decisão pelo Recursos Humanos. Lembre-se que ele pode e deve ser demonstrado incisivamente no mínimo duas vezes durante o processo seletivo. No início da entrevista, após o profissional lhe apresentar a vaga e as condições propostas pela empresa, ele deverá lhe perguntar se realmente o candidato possui interesse na vaga. Se tiver interesse responda que sim e os motivos que fazem ter interesse. Lembre-se de apresentar a pesquisa realizada sobre a organização (dados institucionais e forma de vestir). (Dados obtidos durante entrevista).

F (Família) - Lembre-se que não existe padrão para estrutura familiar. $O$ mais importante é que o Recursos Humanos perceba que o candidato é responsável por alguém (filhos, residência) ou que alguém é responsável e realmente cobra trabalhar (pai, mãe, irmãos). A intenção é entender realmente se o candidato possui atitude estável e está disposto a sacrifícios pelo trabalho. Demonstre também que participa de uma família trabalhadora e todos os familiares trabalham muito e são responsáveis. Outro item importante é a afinidade familiar: fale sobre atitudes suas ao falar do familiar que você mais gosta e explicar por que. (Dados obtidos durante entrevista).

O (Objetivos) - O setor de RH deverá perguntar sobre objetivos. Lembre-se que nesse caso, ele quer saber se o candidato é um profissional que busca algum caminho e cria 
suas metas, ou se é um "barco à vela" solto no mercado. Profissionais com objetivos de curto prazo traçados tendem a superar melhor os desafios do trabalho proposto. Então, deve ser apresentado um objetivo que busca realmente alcançar, de curto prazo. Lembre-se de incluir prazo concreto na resposta. (Dados obtidos durante entrevista).

Hobby - A pergunta do $\mathrm{RH}$ sobre os momentos de descanso ou lazer visam entender a capacidade de trabalho em grupo. Portanto, para responder essa pergunta de forma abrangente, informe algum hobby individual e também hobby realizado em equipe. (Ex: corrida e sair com amigos). (Dados obtidos durante entrevista).

Qualidade - O mais importante em qualidade é contextualizar para o $\mathrm{RH}$ como essa qualidade informada ajuda profissionalmente a executar corretamente e/ou melhor as funções. (Dados obtidos durante entrevista).

Ponto à Desenvolver - Como estamos falando de um ponto a desenvolver, lembre-se de iniciar a resposta conectando o perfil com o futuro. Por exemplo: meu objetivo é crescer muito profissionalmente, para chegar lá, preciso melhorar (ponto a desenvolver). Lembre-se também de informar ao profissional selecionador quais atitudes já está realizando para melhorar "Ponto à Desenvolver". (Dados obtidos durante entrevista).

Formação Acadêmica - Procure iniciar a apresentação sobre cursos realizados e formação acadêmica destacando qualificações e atividades que já realizou que conectem com a vaga e a empresa, e podem ser diferenciais em relação aos demais candidatos. Só depois fale sobre o curso que provavelmente todos os candidatos à vaga possuem. (Dados obtidos durante entrevista).

\section{EXPERIÊNCIA PROFISSIONAL}

Crescimento organizacional - demonstre em cada empresa trabalhada, todo o crescimento interno que teve. Mesmo se não teve promoção de cargo, demonstre 
aumento de responsabilidade ou projetos que assumiu. (Dados obtidos durante entrevista).

Estabilidade Profissional - relate quanto tempo esteve em cada projeto. Não é permitido falar mal de organizações anteriores. Lembre-se que existem apenas quatro formas de sair "bem" de uma empresa trabalhada e todas as saídas devem estar entre elas: crise ou reestruturação, convite para outra empresa, projeção de carreira, encerramento de projeto ou contrato. (Dados obtidos durante entrevista).

Atividades realizadas nas empresas: o $\mathrm{RH}$ buscará informação sobre as atividades anteriores. Lembre-se que o $\mathrm{RH}$ não tem conhecimento técnico específico em cada área de atuação, então, na verdade o que a profissional busca entender é se o candidato já realizou atividades nas empresas que trabalhou, que são compatíveis com as atividades demandadas para a vaga. Dica: utilize palavras similares e/ou iguais as informadas como atividades demandas pelo cargo. Exemplo: o profissional de $\mathrm{RH}$ informa que o cargo precisa de gestão de processos. Se você realmente tiver isso, informe em primeiro lugar ao profissional de $\mathrm{RH}$ quando ele perguntar. Palavras chave de cada processo seletivo (estarão inseridas nas descrições das vagas). 1Verbos e duas palavras seguidas. Ex: "Gerenciar equipes de alto desempenho" que trabalhem em áreas específicas do faturamento da empresa. 2- Termos e Sistemas Operacionais. Ex: Executar constantemente a metodologia "PDCA" (Planejar, desenvolver, corrigir e agir) e lançar atividades no "SAP'. 3- Palavras em inglês: Ex: Possuir "know-how" em atividades específicas. (Dados obtidos durante entrevista).

\section{ENTREVISTA COMPORTAMENTAL}

São vários os modelos de entrevistas, a comportamental com foco em competência é a mais atual. A entrevista é uma técnica de credibilidade em todo o mundo, mas nem sempre usada corretamente. Portanto ao ser convidado para um processo seletivo o candidato poderá ou não seguir todas as dicas citadas acima. (Dados obtidos durante entrevista). 
É importante lembrar que a entrevista comportamental por competência é estruturada para investigar o comportamento passado, mas buscando similaridade com a competência investigada na vaga disponível. Nela não se faz perguntas hipotéticas, de múltipla escolha, indutivas ou fechadas e sim perguntas abertas e específicas (ação passada e previsão de comportamento futuro). As perguntas podem ser divididas em três partes que damos o nome de CAR (contexto, ação e resultado). Como exemplo podemos citar: "relate um exemplo onde você teve que assumir a responsabilidade sobre uma situação, como se fosse o proprietário da empresa, conte como foi? De acordo com Rabaglio (2004) "o candidato deverá responder à pergunta dizendo qual foi a situação, como ele reagiu e quais foram os resultados". Premissa da entrevista comportamental: comportamento passado prediz comportamento futuro. (Dados obtidos durante entrevista).

Interrogado sobre como deve ser a finalização de uma entrevista o mesmo disse que após as perguntas sobre o passado, o RH agradecerá pela participação e perguntará se o candidato possui alguma dúvida sobre a vaga ou processo. $O$ HeadHunter sugere algumas dicas para sanar as dúvidas: pergunte sobre a empresa. (Formas de Crescimento / Cultura) e por último reafirme seu interesse na vaga. (Dados obtidos durante entrevista).

Após a entrevista aguarde o retorno do recrutador, caso em 7 dias o mesmo não retornar ou no prazo acordado o candidato poderá enviar um e-mail agradecendo pela oportunidade de participar do processo seletivo e perguntar se tem algo mais que possa fazer sobre a candidatura na vaga. (Dados obtidos durante entrevista).

As perguntas respondidas pelo HeadHunter da AÇÃOHUNTER seguem os padrões relatados por Rabaglio (2004) que diz que diante de um processo seletivo exercite a autoconfiança, imagine como seria a entrevista, o que poderá ser perguntado e o que poderá ser respondido. Fique atento a apresentação pessoal, aparência, pontualidade, contenha o nervosismo, comprimente as pessoas, olhe nos olhos do entrevistador, demonstre segurança, seja objetivo, demonstre vontade de aprender, fale sempre a verdade. 
E acima de tudo mostre que você é um excelente profissional e quando for contratado coloque tudo que falou na entrevista em prática e gere resultados tanto para o crescimento pessoal como profissional. (LAWSON, 2011).

\section{CONSIDERAÇÕES FINAIS}

As dúvidas são muitas quando o assunto é como se comportar em uma entrevista de emprego e como elaborar um currículo chamativo. Por este motivo o trabalho acima, foi descrito de forma clara e pratica para auxiliar as pessoas neste momento. A problemática em questão: "Como se comportar em uma entrevista de emprego" foi solucionada, pois empatia, calma, objetividade, postura e responder as perguntas de forma a mostrar o recrutador que o candidato gerou resultados com seus conhecimentos, habilidades e atitudes são comportamentos que destacam para aprovação na vaga. O objetivo geral quais são passos para a realização de uma entrevista também foi alcançado através da conversa com o HeadHunter que esclareceu e exemplificou com detalhes este item os quais podemos destacar: pesquisas sobre a empresa, vestimenta adequada a função, apresentação de forma clara e objetiva das experiências, escolaridade, pontos fracos e fortes, estrutura familiar, comportamento, resultados alcançados com experiências anteriores, dentre outros.

Os objetivos específicos também foram atingidos, foi possível descrever técnicas de entrevista, comportamentos, competências, habilidades, como deve ser um currículo completo, pois o mesmo serve como cartão de visita, além de dicas sobre postura, imagem, linguagem corporal.

A hipótese foi confirmada, o candidato terá grande chance de ser aprovado em uma entrevista de emprego se tiver uma boa imagem e um comportamento adequado. Se preparar para uma entrevista e entender as técnicas, estudar sobre a entrevista comportamental por competência garantem destaque no processo seletivo.

Quando se fala em comportamento em entrevistas, passos a serem seguidos, currículos, são dicas que auxiliam o candidato a se destacar e conseguir o cargo 
pretendido. Não existe um padrão de entrevista e não existe um padrão de entrevistado, mas o estudo acima fará com que as pessoas tenham mais chance de serem aprovadas e mostrarem que estão preparadas para este momento tão importante em suas vidas.

\section{REFERÊNCIAS}

ARAÚJO, M. C. de. Recrutamento e Seleção com Base em Competências. Rio de Janeiro. 2012. Disponível em: file://C:/Users/Usuario/Desktop/Artigo\%20para\%Publicação/K Acesso em: 23 de Dezembro de 2018.

CAXITO, F. de A. Recrutamento e seleção de pessoas.Curitiba: Brasil S.A., 2008.

CHIAVEnAtO, I. Gestão de Pessoas: O Novo Papel dos Recursos Humanos nas Organizações. 4. ed. São Paulo: Manole Ltda., 2014.

Planejamento, Recrutamento e Seleção de Pessoal. 5ª. ed. São

Paulo: Atlas, 2004.

GIL, A. C. Métodos e Técnicas de Pesquisa Social. 6. ed. São Paulo: Atlas, 2008. Métodos e técnicas de pesquisa social. 5.ed. São Paulo: Atlas, 1999.

KENNEDY, J. L. Entrevista de Emprego. $1^{\text {a }}$ ed. Rio Grande do Sul: Campos, 1999.

LAWSON, K. Como Impressionar nas Entrevistas de Emprego. 1르 Ed. Rio de Janeiro: Universo dos Livros, 2011.

MARCONI, M. de A. LAKATOS, E. M. Metodologia Científica. 5ª ed. São Paulo: Atlas, 2011.

OLIVEIRA, M. Nas Miras dos Headhunters: Como se Tornar um Profissional Cobiçado. São Paulo: Campus, 2001 apud BOGHOSSIAN, L. F. D. HeadHunting e o 
Processo de Recrutamento e Seleção de Pessoas. Brasília. 2012. Disponível em: http://www.repositorio.uniceub.br/bitstream/123456789/1066/2/20801553.pdf. Acesso em: 23 de dezembro de 2018.

RABAGLIO, M. O. Ferramentas de Avaliação e Performance com foco em Competências. Rio de Janeiro: Qualitymark, 2004.

VERGARA, S. C. Projetos e Relatórios de Pesquisa em Administração. $2^{\underline{a}}$ ed. São Paulo: Atlas, 1998.

VERGARA, S. C. Projetos e Relatórios de Pesquisa em Administração. 3. ed. São Paulo: Atlas, 2000.

\section{APÊNDICE}

\section{Entrevista aplicada ao proprietário da empresa em estudo}

1) Sexo

( ) Masculino ( ) Feminino

2) Idade:

3) Tempo de Serviço:

4) Escolaridade:

5) Como deve ser a fase de preparação para o processo seletivo?

6) Qual o primeiro passo ao iniciar a entrevista?

7) Quais os cuidados devemos tomar na antessala do processo seletivo?

8) Como se comportar durante a entrevista?

9) Como deve ser a finalização de uma entrevista? 


\section{ANEXO}

\section{A - Como Elaborar um Currículo}

\section{Curriculum Vitae}

Faça o cabeçalho de forma objetiva colocando os principais dados. Não precisa colocar se tem filhos e números de documentos. Não use e-mail com apelidos, seja profissional.

\section{Nome:}

Idade:

Estado civil:

Endereço Residencial:

Telefone:

E-mail:

\section{Área de Interesse}

Seja claro e direto para que o mercado entenda o que você está buscando.

\section{Síntese Profissional}

Faça uma síntese geral do seu currículo, colocando formação, experiências e principais características.

\section{Formação:}

Escreva a formação da mais recente para a mais antiga.

Idiomas: 
Coloque os idiomas que você está cursando e o nível em que está (básico, intermediário, avançado).

\section{Experiência profissional:}

As experiências profissionais devem ser descritas da mais recente para a mais antiga. Se as mesmas forem muitos extensas coloque somente as que estão de acordo com seu objetivo profissional. Ao descrever suas atividades ou experiências seja sucinto, porém completo. É importante lembrar que o currículo pode ter uma ou mais páginas, porém aprenda a ser objetivo, diga o suficiente. Faça uma síntese das principais realizações colocando os resultados e destaque os principais projetos

\section{Empresa:}

\section{Cargo:}

Principais atribuições: coloque em tópicos

Principais Projetos e Resultados Alcançados: coloque em tópicos

\section{Empresa:}

\section{Cargo:}

Principais atribuições:

\section{Empresa:}

\section{Cargo:}

Principais atribuições:

Principais Projetos e Resultados Alcançados:

\section{Cursos Extra Curriculares}


Descreva seus cursos extracurriculares do mais recente para o mais antigo. (Coloca todos os cursos que você fez desde os profissionalizantes até os de curta duração).

\section{Certificações}

Descreva suas certificações da mais recente para a mais antiga.

\section{Premiação e outros}

Descreva suas premiações, carteira de habilitação, disponibilidade para viagens e mudança de cidade.

Formatação: Arial ou Times New Roman 12. Cuidado com erros de português.

Foto: Colocar $3 \times 4$, mas com terninhos pretos com blusa branca por baixo ou camisa social branca. (Mas a foto não é obrigatória).

Enviado: Dezembro, 2019.

Aprovado: Janeiro, 2020. 